\title{
Historia e Memória no romance Um defeito de cor ${ }^{*}$
}

\author{
History and Memory in the novel Um defeito de cor
}

\author{
Daiana Nascimento dos Santos***
}

\begin{abstract}
Resumo: O presente artigo propõe que Um defeito de cor [2006] (2010) da escritora brasileira Ana Maria Gonçalves oferece uma metáfora do Brasil por meio de construções simbólicas que se sobrepõem ao estritamente literário e dialogam com aspectos históricos, culturais e literários que formam a multifacetada sociedade brasileira. Neste sentido, consideramos que a personagem histórica Luísa Mahin representa uma metáfora de um Brasil contemporâneo, pois sua história pessoal sintetiza a emancipação do coletivo de mulheres negras.
\end{abstract}

Palavras-chave: Metáfora do Brasil. Ana Maria Gonçalves. Luisa Mahin.Mulheres negras

\begin{abstract}
This paper proposes a color defect [2006] (2010) offers a metaphor of Brazil through symbolic constructions overlapping the strictly literary and dialogue with historical, cultural and literary aspects that make up the multifaceted Brazilian society. In this sense, we consider that the historical character Luísa Mahin is a metaphor of a contemporary Brazil because his personal history epitomizes the emancipation of the group of black women
\end{abstract}

Keywords: Brazil's Metaphor.Ana Maria Gonçalves. Luisa Mahin. Black women

Recibido: 14 julio 2016

Aceptado: 22 septiembre 2016

\section{Antecedentes}

Ana Maria Gonçalves (1970) teve de percorrer os recônditos da historia do Brasil para se consolidar como uma das escritoras mais importantes da literatura brasileira contemporânea. Esse itinerário se concretiza graças à repercussão do romance Um defeito de cor (2006), seu segundo livro.

\footnotetext{
* O presente artigo está vinculado ao projeto "Pasados que se entrelazan: representaciones contemporáneas sobre (¿el fin?) de la esclavitud” de CONICYT/FONDECYT de Postdoctorado, Folio 3160158.

** Brasileira, Doctora em Estudios Americanos, Pesquisadora Pós- doutoramento FONDECYT, Centro de Estudios Avanzados, Universidad de Playa Ancha, Chile, daiana.nascimento@upla.cl
} 
Num estilo memorial, Um defeito de cor percorre quase cem anos de historia da escravidão, da opressão escravagista e de fatos importantes da historia do Brasil e da África do século XIX. Esse contexto é narrado sob a perspectiva feminina, proporcionando uma discussão importante sobre as experiências das mulheres como escrava/escravizada para os estudos de gênero e de escravidão. A obra resgata a narrativa a partir das vozes silenciadas pelo poder e traz à colação a possibilidade de múltiplas versões sobre os acontecimentos ocorridos no Brasil e na África do século XIX (Pimentel 2011). Para tal empreitada, Gonçalves assegura que o ponto de partida foi ter encontrado por acaso, o manuscrito de Luisa Mahin /Kehinde durante o período em que morava na Ilha de Itaparica na Bahia. Nesse bojo, Gonçalves visita as fontes da historia colonial, reinventa o passado e promete trazer à baila os recônditos da historia brasileira, num diálogo que se estabelece com o leitor através da voz da própria narradora.

Um defeito de cor recebeu uma considerável recepção da crítica literária e foi galardoado com diversos prêmios no Brasil e no exterior, entre eles, o Prêmio Casa de las Américas na categoria literatura brasileira em 2007.

A configuração histórica e discursiva do Brasil -e da América Latina- é uma construção complexa e ambivalente, porque foi articulada por uma série de serendipidades ${ }^{1}$ quanto à formação do seu imaginário. Os indícios iniciais dessas casualidades se notam no evento de seu "descobrimento", se estendendo ao longo de sua história e alcançando, indubitavelmente, outros acontecimentos em diferentes conjunturas no continente.

Dentro desse marco, a literatura tem sido um dos cenários mais representativos desses processos de elaborações e experimentos, e o romance Um defeito de cor constitui um exemplo dessa experiência significativa. Nesse bojo, a análise deste artigo se centra na ficcionalização do imaginário do cotidiano de uma escrava liberta mediante uma recreação literária que abarca quase cem anos de história individual e coletiva do Brasil colonial. A obra narra a saga de Kehinde, também conhecida como Luísa Mahin/Gama, cuja trajetória está marcada por uma tragédia familiar carregada de mortes, violência, estupros, perdas na África e, portanto, pelas experiências de escravização/escravidão no Brasil. Entretanto, a sua história não é marcada apenas por tragédias, mas também por circunstâncias de sobrevivência, revitalização, superação e emancipação feminina - tanto no Brasil como na África.

Um defeito de cor reconstrói a experiência traumática da escravização/escravidão a partir de uma perspectiva subjetiva feminina por meio de uma narração em primeira pessoa.

\footnotetext{
${ }^{1}$ De acordo com a definição que expõe Gonçalves no prólogo da novela: "Serendipidade", assim, começou a ser usada para descrever o que ocorre se descobrirmos ou encontrarmos alguma coisa pela qual procuramos, porém, para tal encontro já teríamos que estar, como se diz, preparados. Ou seja, que necessitamos ter, ao menos, um pouco de conhecimento sobre o que "descobrimos" para que o feliz momento de serendipidade não aconteça sem que nos demos conta). (GONÇALVES, 2010, p.09)
} 
A história se desenvolve num período que compreende quase cem anos de vida, em que os eventos estão relacionados com a rotina de personagens (históricos, fictícios, divindades, ancestrais divinizados etc.) num cenário de fundo que remete ao Brasil e à África do século XIX. Na apropriação literária desse panorama, a escravização/escravidão é apresentada a partir de uma perspectiva intensamente dinâmica e complexa de trocas e de relações de diversas índoles entre europeus e africanos, assim como alterações importantes nos constantes processos de transformação social e de redefinição da sociedade colonial e escravagista da época.

Esse cenário funciona como contexto importante para propor uma reformulação da África em relação à escravização/escravidão, portanto, oferece um deslocamento significativo de elementos literários, de expectativas, de olhares, de relatos e de ficcionalizações. A par desse horizonte, nota-se, no romance, um ponto de vista contemporâneo de consciência social que explora infinitas possibilidades para ler a história da escravização/escravidão sob um olhar feminino. A obra narra a busca incansável da protagonista por seu filho, fruto de uma relação com um português que entrega o menino de sete anos a outra pessoa, como pagamento por uma dívida contraída em jogo de azar. Por trás desse fato, vai surgindo um contexto que abrange importantes eventos históricos do Brasil colonial, de modo que os resquícios da emancipação do Brasil vão se sobrepondo, em diacronia, com a libertação da protagonista como mãe, mulher e agente social; tal contexto a transforma numa personagem mítica e histórica dentro de sua própria narrativa.

Por outro lado, o fio temático que se tece junto à narrativa se desprende da complexidade histórica e da imaginação criativa evocada pela voz da própria autora da obra, pois a narradora se reveste de matizes transcendentais para conceber este projeto de escrita, já que acredita receber inspiração da protagonista para terminar o aludido romance, como expressa no prefácio:

Para facilitar a leitura, tomei a liberdade de pontuá-lo, dividi-lo em capítulos e, dentro de cada capítulo, em assuntos. Espero que Kehinde aprove o meu trabalho e que eu não tenha inventado nada fora de propósito. Acho que não, pois muitas vezes, durante a transcrição, e, principalmente durante a escrita do que não consegui entender, eu a senti soprando palavras no meu ouvido (GONÇALVES, 2010, p.17).

Neste sentido, o leitor se vê em um texto onde não fica claro o limite entre a ficção e a realidade da personagem Luísa Gama/Mahim ${ }^{2}$, quem, na novela, prefere o nome africano de Kehinde. Segundo a autora, o romance se configura a partir de um manuscrito encontrado ao acaso que lhe oferecia dados sobre a personagem e seu filho desaparecido que, hipoteticamente, poderia ter sido o poeta romântico Luis Gama ${ }^{3}$, como se observa no fragmento da novela: "Pensei também no nome que daria ao bebê. Havia um nome no ar

\footnotetext{
${ }^{2}$ Mahín é uma referência à tribo Mahín, grupo étnico originário do Golfo de Benín que, no século XVIII, foi dominado pelos mulçumanos.

${ }^{3}$ É considerado um dos precursores da literatura brasileira com a abordagem temática do 'escravo'. Luis Gama (1830-1882) foi filho de uma africana livre e de um senhor branco, que o vendeu como escravo aos dez anos. Foi um exímio orador libertário, escreveu versos satíricos sobre o panorama da sociedade brasileira daquele período, principalmente, no que se refere ao tema da escravidão. Gama é o patrono da Academia Paulista de Letras.
} 
que eu ainda não tinha conseguido entender, e se o Alberto insistisse em dar o nome de branco de Luiz, eu concordaria, mas também daria outro nome, um nome africano [...]". Desse modo, o romance pretende recuperar a figura histórica de Luísa Gama/Mahin a partir dos recursos oferecidos pela literatura, de maneira a recriar, literariamente, a trajetória da personagem através da experiência vibrante da serendipia, como bem explica a autora no prólogo:

Um defeito de cor é fruto da serendipidade. Ele não só contém uma história, como também é consequência de uma outra história que, depois de pensar bastante, percebi que não posso deixar de contar. Até poderia, mas, além de não estar sendo honesta, também estaria escondendo o que ajuda a fazer deste livro um portador de histórias especiais (GONÇALVES, 2010, p.09-10).

Nesse viés, a literatura aparece como um espaço de confabulação dinâmica, cuja elaboração se pode observar no panorama do romance estudado. Esse horizonte temático e de achados significativos se elabora mediante alterações simbólicas que expõe o mesmo imaginário, fato que tem sido recorrente na configuração do pensamento latino-americano e na historiografia literária brasileira.

Nesse sentido, propomos pensar numa metáfora de Brasil, entendendo-a a partir da representação literária de alguns arquétipos que sintetizam a idéia abstrata da identidade nacional, e que se vêem cristalizados em diferentes momentos da literatura brasileira. Para compreendê-los com esse significado, devem ser considerados três períodos específicos da literatura brasileira, cujas abordagens elaboram diversos aspectos culturais e sociais que constroem uma expressão de identidade nacional brasileira.

O primeiro período tem como marco, o século XIX, quando o modelo social estava representado pelo homem branco de origem português, católico e vinculado à oligarquia, sujeito que tinha escravos, mulheres, família e filhos sob o seu poder. Esse ambiente se retrata na produção literária do Romantismo, já que, na primeira geração desse movimento literário, tenta evocar a figura do indígena; sobre esse tema, os romances de José de Alencar são um exemplo. Posteriormente, a terceira geração do Romantismo, marcada por um forte ideal libertário, dirige sua atenção à figura do escravo; assim, Castro Alves é reconhecido como "o poeta dos escravos", mesmo que ele pertencesse a uma família oligárquica. Nesse sentido, situamos como metáfora de Brasil, para esse período, a figura do indígena em obras românticas como $O$ Guarani, Iracema de José de Alencar, entre outras; e, das mestiças com características de branco como a protagonista de $A$ moreninha, de Joaquim Manuel de Macedo, ou A escrava Isaura de Bernardo Guimarães. Essas figuras resumem a idéia abstrata da identidade brasileira em gestação, ainda que o que predomine seja a representação dessas figuras revestidas com características de "branco". Dessa maneira, é convalidado o modelo social representado pelo homem branco, já que tanto o "índio" como o "negro" estão construídos de acordo com o seu olhar, literalmente, nesse período.

A partir desse momento, surgem as discussões sobre o poder do homem branco; além, das teses racistas e de outras teorias que começam a circular no âmbito intelectual, político e cultural brasileiro. Nesse contexto, o cenário oligárquico vai dando lugar a outro panorama social e cultural correspondente à república. 
Além disso, situamos o segundo período para o inicio do século XX, pois, neste momento, se produz uma mudança significativa nesse cenário, já que o Brasil assume condições diferentes que refletem a pujança de um país em desenvolvimento, com uma economia ainda latifundiária, mas com um setor econômico industrial em plena formação. Esse novo cenário dá lugar a diversos debates acerca da interpretação do país, especialmente, a raiz das mudanças que chegavam às esferas sociais, históricas e culturais desse período.

O Modernismo, como movimento cultural se constitui levando adiante a ruptura com os modelos estéticos anteriores, pois renova o panorama artístico e a sociedade brasileira daquele período, principalmente nos campos da literatura e das artes plásticas. A enunciação se concentra nas particularidades da dialética local e no cosmopolitismo que inspiram as vanguardas européias do período anterior à Primeira Guerra Mundial. Desse laboratório cultural emergem as novas linguagens e expressões modernas dos movimentos artísticos e literários europeus que foram, pouco a pouco, assimilados pelo contexto brasileiro da época e que o reelaboraram com elementos da cultura brasileira. A Semana da Arte Moderna - realizada em São Paulo, em 1922 - é o cenário inicial deste banquete antropofágico, sendo Macunaíma (1928), de Mário de Andrade, a principal expressão desse laboratório cultural que sintetiza os esquemas culturais e estéticos cunhados pela primeira geração do Modernismo. A representação de Macunaíma se revela como uma metáfora do Brasil, pois resume a idéia abstrata do mosaico cultural representativo da identidade brasileira a partir das três raízes primordiais que unem, entre si, o processo de miscigenação racial e cultural.

Ainda que se possa detectar uma visão mais ampla sobre a representação social correspondente a esse momento, o padrão social se desloca do campo para as grandes metrópoles, a mulher passa a assumir um papel distinto do contexto anterior; ademais, existe uma mudança superficial na visibilidade do descendente de escravo. Em relação a esse último aspecto, Gilberto Freyre, no seu texto clássico Casa Grande \& Senzala (1933), elabora um retrato da formação nacional brasileira a partir das três etnias que, segundo ele, contribuíram harmonicamente para tal compêndio. É importante ressaltar que Freyre era neto de fazendeiros no Nordeste do Brasil, e escreveu sob o ponto de vista de sua classe social. Da "janela da Casa Grande", Freyre apresenta outra representação a esse contexto, e o faz de uma maneira que "suaviza" a violência da escravidão no Brasil, atribuindo uma "visão romântica do engenho de açúcar", o que de certa forma, reforça o mito da democracia racial. Em contrapartida, Um defeito de cor, rebate essa visão romântica, pois revela o imaginário violento da Casa Grande (GONÇALVES, 2011) a partir da representação literária da rotina de uma escrava.

Nesse período, forja e reforça o mito da democracia racial na sociedade brasileira, delimitando-se como um conceito que ainda está presente no pensamento social do Brasil. Em relação ao exposto, Abdias do Nascimento chama a atenção para este aspecto no livro O genocídio do negro brasileiro (1978):

[...] erigiu-se no Brasil o conceito da democracia racial: segundo esta tal expressão supostamente refletiria determinada relação concreta na dinâmica da sociedade brasileira: que pretos e brancos convivem harmoniosamente, desfrutando iguais 
oportunidades de existência, sem nenhuma interferência, nesse jogo de paridade social, das respectivas origens raciais ou étnicas (NASCIMENTO, 1978, p.41).

Abdias do Nascimento enfatiza a condição social e as oportunidades para o grupo coletivo negro, deixando claro que estes não estão em pé de igualdade com os brancos. $\mathrm{O}$ que aumenta o estranhamento sobre a existência da democracia racial no Brasil é se, de fato, o país sempre foi visto internacionalmente como uma democracia racial, por que o Estado brasileiro recentemente implantou um sistema de ação afirmativa? Talvez, a resposta se mostre menos precisa no projeto literário de Um defeito de cor, cujo pano de fundo revela, implicitamente, sua tendência contemporânea por trás da ficcionalização do passado da escravidão, a partir de uma perspectiva que revalida/reivindica a identidade negra como identidade brasileira, especialmente se considerarmos que a proposta da ação afirmativa ainda é bastante controvertida nessa sociedade, pois, muitos - inclusive alguns intelectuais influentes - continuam pregando e crendo em uma sociedade racialmente harmônica ${ }^{4}$.

Haja vista que num terceiro momento da literatura brasileira, colocamos Um defeito de cor, obra que se pode entender como uma metáfora do Brasil contemporâneo, dentro do argumentado anteriormente, pois, sinaliza, num panorama atual em que as novas conjunturas sociais, políticas e econômicas, os intensos processos migratórios inter/transcontinentais, os movimentos sociais de diversas índoles, a luta pelos direitos das minorias, os debates relacionados ao universo negro - como as ações afirmativas, estreitamento de laços com os países africanos, intercâmbio de discentes e docentes africanos e brasileiros, entre outros -, instigam a repensar/reconfigurar o imaginário da identidade brasileira. Esta prospectiva deu lugar a intensas discussões, problemáticas, tensões e divergências, posto que os fatores anteriormente mencionados comprometam as falácias do imaginário social sobre a identidade brasileira, porque desestabilizam mitos como a democracia racial, a cordialidade, a integração harmônica "[...] que disfarçam a exclusão e a segregação dos mais fracos, dos mais pobres, dos diferentes do padrão definidor da identidade defendida" (GONÇALVES, 2010, p.11), como bem apontaram as críticas literárias brasileiras Chiappini e Bresciani (2002) em Literatura e cultura no Brasil: identidades e fronteiras.

Neste sentido, Um defeito de cor desestabiliza o padrão determinante do imaginário social da identidade brasileira, dado que o discurso literário esboça uma proposta de reinvenção da história, conferindo voz aos marginalizados historicamente. O texto transcende os conhecimentos do passado, e, por sua vez, lhe outorga um novo protagonismo ao grupo coletivo negro. Para conseguir isso, o texto literário compromete a

${ }^{4} \mathrm{O}$ Estatuto da Igualdade Racial, como é conhecida a Lei 12.288/2010, promove o ingresso de afrodescendentes por meio de cotas nas universidades, empregos públicos etc. Esta proposta pretende incentivar uma melhor mobilidade social, mas, ao mesmo tempo, provocou a inconformidade de grande parte dos setores tradicionais brasileiros que tentam boicotar de várias formas estas vitórias. Sobre este assunto, ver o documentário 'Raça' (2013) do cineasta brasileiro Joel Zito Araújo, que retrata o tenso processo de votação da mencionada lei e de outras situações que envolvem a condição social do afrodescendente no Brasil. 
legitimidade dos mitos historicamente determinantes da identidade brasileira, reclama o papel do coletivo negro no processo histórico do Brasil e instala, a partir de uma perspectiva contemporânea, a importância do debate sobre o universo negro no contexto histórico, literário, cultural e social.

Deste modo, é revelada a tendência contemporânea do romance de abordar uma temática atual mediante a ficcionalização do passado de escravidão de homens e mulheres negros. Nessa empreitada, Um defeito de cor propõe uma nova interpretação da história através de uma leitura crítica do passado sob um olhar analítico do presente (Santos, 2015). $\mathrm{O}$ passado escravagista funciona como um pretexto para questionar o contexto atual em que se discute o projeto de ações afirmativas e, ao mesmo tempo, insiste em mostrar o papel de protagonistas de homens e mulheres negras além da ficção literária.

Além disso, chama a atenção sobre o contexto escravagista apropriado pelo discurso literário através da perspectiva da voz duplamente marginalizada pela história hegemônica: a voz negra e feminina. Neste sentido, a partir de uma análise contemporânea, se pode dizer que Um defeito de cor oferece uma metáfora de Brasil através da representação da personagem Kehinde, visto que sua trajetória extraordinária condensa a idéia abstrata da emancipação do coletivo feminino, e se encontra representada nos diversos episódios de luta e resistência ficcionalizados no romance. Além de vincular esse contexto de escravidão com a exploração laboral e com o apagamento do imaginário desse grupo coletivo, cabe questionar que lugar ocupa a mulher negra nesse contexto, e como viveram essas experiências na Casa Grande. O romance relata a procura de um protagonismo coletivo feminino, visto que Kehinde representa o conjunto de mulheres afrodescendentes que tiveram uma experiência histórica violenta no período escravagista, fato que ainda se observa, no presente, sob distintas modalidades de exploração e violência.

Essa situação se revela na cena que segue, onde Kehinde - adolescente - comenta sobre a aproximação do seu proprietário. Trata-se de um ato de violência muito comum cometido contra as mulheres escravas.

Em uma das visitas, o sinhô José Carlos me olhou de modo estranho, pedindo que o Cipriano me levasse até ele, quando me fez abrir a boca e olhou meus dentes. Depois, com a ponta da vara que usava para cutucar o cavalo, levantou a barra da minha saia e olhou minhas personas. Olhou também paraa minha bata na altura dos peitos, que já estava quase tão grandes quanto os da Felicidade. À noite, a Ignácia passou a mão sobre a minha cabeça e disse que eu não era mais uma menina, que já tinha corpo de mulher, e perguntou se meus sangues já tinham aparecido (GONÇALVES, 2010, p.151).

No subcapítulo “A posse”, Kehinde relata essa experiência violenta:

O sinhô José Carlos perguntou se eu achava que ia conseguir escapar e nada respondi, nem mesmo olhei para ele, porque achava que sim, que depois do acontecido ele não ia mais insistir. Mas, além disso, da insistência, ele conseguiu ser muito mais vingativo do que eu poderia imaginar, ao entrar no quarto e dizer que a virgindade das pretas que ele comprava pertencia a ele [...] (GONÇALVES, 2010, p.170).

O estrato acima aponta sinais que permitem recusar a idéia "romântica" da Casa Grande, como já se comentou, dado que evidencia a relação de poder entre amo e escravo: 
os senhores consideram esses últimos como suas propriedades, com o direito de usá-los segundo os seus desejos, num cenário onde o padrão de poder implica que os senhores escravocrata sempre serão senhores e os escravos patrimônio deles. Como já foi referido anteriormente na fala de Abdias do Nascimento, que dialoga com Gonçalves: "A norma consistia na exploração da africana pelo senhor escravocrata, e este fato ilustra um aspectos mais repugnantes do lascivo, indolente e ganancioso caráter da classe dirigente portuguesa" (2010, p.61).

Considerando o antes mencionado, é de suma importância observar o papel da mulher negra no contexto da escravidão e nos processos históricos brasileiros, principalmente, porque, nesses espaços, ocupa um lugar de destaque usualmente assumido por homens, e, ao mesmo tempo, rejeita o papel de vítimas e/ou de personagens secundários. Por trás desses processos abordados, se visibiliza no romance, a relação de dependência de poder, que é exercido pelo sujeito feminino, o que ainda merece um estudo mais profundo que vincule problemáticas mais amplas e globais. De diversas formas e perspectivas, a participação feminina tem sido uma constante nos processos históricos, principalmente, da mulher negra, ainda que nem sempre tenha sido dessa forma, como já foi comentado num outro momento.

Desta maneira, entende-se que Um defeito de cor se configura a partir das vozes silenciadas pelo poder, e mostra o perfil de uma heroína vanguardista que não se ajusta ao modelo legitimado pela literatura brasileira tradicional, que exige seguir a proposta de "enegrecer o feminismo" em nível literário. Nesse bojo, a escritora brasileira Sueli Carneiro argumenta

O que poderia ser considerado histórias o reminiscências do período colonial permanecem, entretanto, vivas no imaginário social e adquirem novas roupagens e funções numa ordem social, supostamente democrática, que mantêm intactas as relações de gênero, segundo a cor ou "raça" instituídos no período escravagista. As mulheres negras tiveram uma experiência histórica diferenciada, que o discurso clássico sobre a opressão da mulher não salientou. Assim como tampouco se nota a diferença qualitativa que o efeito da opressão sofrida teve e ainda tem na identidade feminina das mulheres negras (2001:01)

A importância de responsabilizar-se por um projeto literário que permite reflexionar sobre a proposta de "enegrecer o feminismo" reivindica o papel de protagonista da mulher negra nas diversas camadas da sociedade brasileira tanto ao nível histórico, literário, político, como em qualquer papel que desempenhe nesta sociedade. É importante salientar que o eixo central enfatiza um sujeito coletivo feminino (mulheres escravas e negras) e postula uma alteração significativa do papel representativo para as discussões sobre a história da escravidão a partir de um olhar feminino, o que se reforça na afirmação "A mulher negra tem história" (1987), das ativistas Rufino e Pereira (1987),do Movimento Negro Feminino.

Trata-se, portanto, de um projeto ficcional que resgata a história sob uma perspectiva dos vencidos, ou dos "vultos negros da história do Brasil", como expõe Nélson

\footnotetext{
${ }^{5}$ Disponível em: http://www.unifem.org.br/sites/800/824/00000276.pdf. Carneiro, Sueli. "Enegrecer o feminismo".
} 
Silva de Oliveira (2001), e, com este objetivo que propõe uma função de protagonista para o sujeito feminino como mulher e negra. Tal escritura pode se circunscrever ao marco discursivo que se pergunta por uma metáfora do Brasil contemporâneo, metáfora que se concebe como o processo de uma autêntica emancipação social e participação do grupo coletivo feminino - das minorias econômicas e políticas - no cenário representacional.

A partir dessa perspectiva, a metáfora contemporânea identificada diferencia-se das do Romantismo e do Modernismo pelo deslocamento do arquétipo do padrão social e da perspectiva que confere papel principal à mulher negra - grupo coletivo negro e aos marginalizados historicamente. Essa metáfora compromete os mitos representacionais de outros períodos, pois reforça a luta social por direitos e a emancipação social para a mulher negra, principalmente, se considerarmos o panorama econômico do Brasil nas últimas décadas, onde há um desdobramento considerável da nova classe média brasileira (Classe C), que está composta por mais da metade de mulheres afrodescendentes. É neste período de intensas mudanças sociais que se observam mudanças de diversas índoles na configuração do imaginário social da identidade brasileira, tal como comentamos brevemente no parágrafo anterior.

Por esse motivo, observamos mudanças importantes nesta sociedade onde novos atores, espaços e conjunturas sociais reivindicam um lugar diferente neste processo de desconstrução do imaginário sobre a identidade determinante, e, por conseguinte, forjam uma nova metáfora para o Brasil.

Esse panorama reforça as discussões sobre a identidade brasileira contemporânea e, ao mesmo tempo, traz à luz as resistências e as desigualdades sociais que salientam essas relações nas diferentes esferas deste imaginário social. Nesse conjunto de estratégias, a literatura brasileira contemporânea funciona como um espaço dinâmico para a confabulação dessa terceira metáfora, pois há uma polifonia de vozes femininas - e de outras minorias - que se apropriaram do universo criativo da literatura para, através dele, oferecer um deslocamento de protagonismo, de elementos literários, de ficcionalizações e perspectivas.

Um defeito de cor é um exemplo concreto desse projeto criativo onde emerge uma voz feminina e negra que reinventa a história, valida o universo negro na identidade brasileira e reivindica o papel que cumpriu a mulher negra nesses processos, ainda que por muito tempo se tenha dado pouca relevância. Seguindo esses aspectos, argumentamos que o romance abre uma reflexão sobre a revisão do passado escravocrata do Brasil, pois instiga uma correção simbólica desse contexto doloroso e de seus efeitos históricos vigentes até o presente. A partir da reinvenção da história, Um defeito de cor convida o Brasil a repensarse e reelaborar-se com o propósito de redefinir suas configurações dentro dos processos de constantes mudanças no âmbito pós-moderno. Situação que talvez seja o começo de um processo de (re) definição da identidade brasileira nesse contexto.

\section{Referências}

ANDRADE, Marcos Roberto Teixeira de. "A visão periférica da História em Um defeito de cor de Ana Maria Gonçalves”, Comunicações do Simpósio Internacional de Literatura, Crítica, Cultura III: Interfaces, Minas Gerais: Universidade Federal de Juiz de Fora,2009. 
AÍNSA, Fernando. Nueva Novela Histórica y la relativización del saber histórico.La Habana: Casa de las Américas, 1996.

CÂNDIDO, Antônio. Literatura e sociedade: estudos de teoria e história literaria. São Paulo: Co. Ed. Nacional, 1973.

CAPUANO, Cláudio de Sá. "História e africanidade em Um defeito de cor, de Ana Maria Goncalves". En: Alguma prosa: ensaios sobre literatura brasileira contemporánea. Giovanna Dealttry, Masé Lemos y Stefania Chiarelli. Rio de Janeiro: 7Letras, 2007.

CHIAPPINI, Ligia y Bresciani, Maria Stella (orgs.) Literatura e cultura no Brasil: identidades e fronteiras. São Paulo: Editora Cortez, 2002.

DECCA, Edgar Salvadori de. "Tal pai, qual filho? Narrativas da identidade nacional". Literatura e cultura no Brasil: identidades e fronteiras. Chiappini, Ligia y Bresciani, Maria Stella (orgs.) São Paulo: Editora Cortez, 2002, pp. 15- 28.

GONÇALVES, Ana Maria. Um defeito de cor. Rio de Janeiro: Record, 2010. . Inspiração e viagens através da diáspora: uma entrevista com Ana Maria Gonçalves. AfroHispanic review, Nashville: Vanderbilt Univ., ${ }^{\circ} 30$ (2011): pp. 167- 181.

JAHN, Janheinz. Las literaturas neoafricanas. Madrid: Ed. Guadarrama, 1971.

NASCIMENTO, Abdias do. O genocidio do negro brasileiro. Rio de Janeiro: Ed. Paz e Terra, 1978.

OLIVEIRA, Lúcia Lippi. “A invenção da memória do povo brasileiro”. Revista Estudos Históricos, Rio de Janeiro, Centro de Pesquisa e Documentação de História Contemporânea do Brasil da Fundação Getúlio Vargas, jan.-junho, n³9, 2007: pp. 157-160.

OLIVEIRA, Nélson Silva de. Vultos negros na história do Brasil: Guia de direitos do brasileiro afro- descendente. Brasília: MJ/ SEDH, 2001.

PIMENTEL, Clara Alencar Villaça. "Eu vim de lá pequenininho, alguém me avisou pra pisar neste chão devagarinho": Diálogos diaspóricos entre Um defeito de cor, de Ana Maria Gonçalves e Beloved, de Toni Morrison. Tesis para optar al grado de Maestríaen Letras, Universidade Federal de Juíz de Fora, Minas Gerais, Brasil, 2011. Recurso en línea: http://www.bdtd.ufjf.br/tde_arquivos/18/TDE-2011-08-25T084649Z968/Publico/claraalencarvillacapimentel.pdf (Última visita: 08-07-2014)

RUFINO, Alzira; Pereira, Maria Rosa; Iraci, Nilza. Cartilha: mulher negra tem história. Santos: Eboh Ed. e Livraria Ltda, 1987.

SANTOS, Daiana Nascimento dos. El océano de fronteras invisibles: relecturas históricas sobre (¿el fin? de) la esclavitud en la novela contemporánea. Madrid: Editorial Verbum, 2015.

CARNEIRO, Sueli. Enegrecer o feminismo. Disponível em: 〈http://www.unifem.org.br/sites/800/824/00000276.pdf $\rangle$. [S.l; s.n]. Acessoem: 15 jun. 2016 